\title{
Cátedra Unesco en Comunicación y Cultura de Paz
}

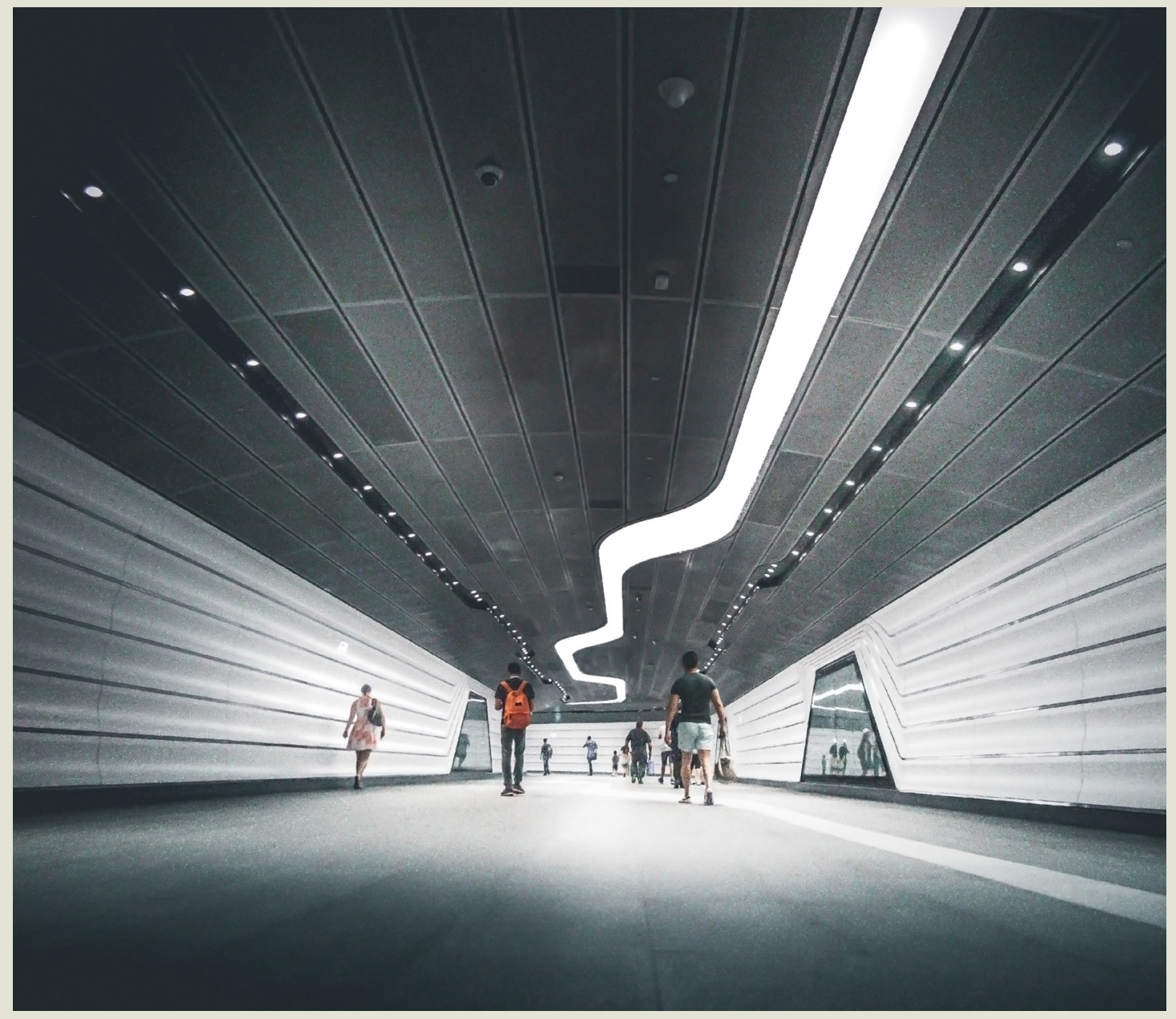





\title{
A prueba del otro
}

\author{
Eric Landowski \\ (traducción: Desiderio Blanco)
}

Recibido: $13 / 7 / 2016$

Aprobado: 2/8/2016

\begin{abstract}
Resumen. Delimitar un campo de estudio y fijar un corpus de textos que servirán de base al análisis no son las únicas tareas que enfrenta la semiótica. Hay otra dimensión, la de la intersubjetividad, que plantea interesantes problemas entre el analista semiótico y sus fuentes de información. Esa otredad tiene un marco ético, de cuyo riguroso cumplimiento depende el estudio de un determinado asunto sin caer en estereotipos ni deformaciones. Se trata, pues, de superar la mirada unívoca y excluyente del investigador para dar paso a la voz del otro, a ese espacio simbólico de diálogo e intercambio cultural que enriquece perspectivas y establece corrientes de empatía entre el estudioso y su objeto de estudio.
\end{abstract}

Palabras clave: semiótica / antropología / otredad / intersubjetividad / análisis

\section{Otherproof}

AвSTRAct. Delimiting a field of study and fixing a corpus of texts that will serve as the basis for the analysis are not the only tasks facing semiotics. There is another dimension, that of intersubjectivity, which raises interesting problems between the semiotic analyst and his sources of information. That otherness has an ethical framework, whose rigorous compliance depends on the study of a certain matter without falling into stereotypes or deformations. It is therefore a question of overcoming the univocal and exclusive view of the researcher, to give way to the voice of the other, to that symbolic space of dialogue and cultural exchange that enriches perspectives and establishes currents of empathy between the student and his object of study.

Keywords: semiotics / anthropology / otherness / intersubjectivity / analysis 


\section{En busca del objeto}

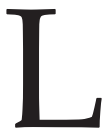

a semiótica y la antropología no solo tienen en común, en un plano muy general, la ambición de circunscribir aquello que constituye al mismo tiempo la unidad y la diversidad de las formas del entendimiento y del imaginario humanos. Comparten también, por lo menos en sus versiones de inspiración estructural, la idea según la cual la realización de ese proyecto pasa por el recurso a procedimientos de análisis empírico, aplicados a objetos que tienen, como se dice en semiótica, el estatuto de "manifestaciones". Poco importa que se trate de textos o de prácticas (de "mitos" o de "ritos"), de obras artísticas o de productos de la industria, de comportamientos individuales o de usos colectivos, de normas o de instituciones, siempre que presenten un carácter observable, articulado y, por lo tanto, significante. Incluso para emprender una investigación determinada, es preciso fijar cuáles, entre la infinita variedad de manifestaciones que se ofrecen, son las que se consideran pertinentes.

De ahí un primer problema, de orden puramente práctico en apariencia, pero cuyas implicaciones son cruciales para ambas disciplinas. En semiótica, se trata de la constitución del corpus, es decir, de la elección de los textosobjetos y de su delimitación, o bien, cuando el análisis recae no sobre textos sino sobre prácticas (como sucede corrientemente en el caso de la sociosemiótica), de la búsqueda de criterios adecuados para la clausura del campo de observación. En la antropología, el problema correspondiente concierne a la definición de la conducta que se ha de observar sobre el terreno, con vistas a la recolección de los datos. Sin embargo, en conjunción con esas cuestiones iniciales por resolver sobre el punto de vista metodológico, surgen dificultades más arduas en un segundo plano, de orden teórico, y hasta epistemológico. Ellas también se pueden formular, a grandes rasgos, en los mismos términos para ambas disciplinas. Tienen que ver con una paradoja bastante conocida.

Por un lado, para analizar un corpus o interpretar datos es preciso, obviamente, que estos hayan sido previamente recogidos, puesto que constituyen los elementos que el investigador va a analizar o a interpretar. Pero, por otro lado, dado que no se puede recoger determinado elemento sin descartar otros, o sea, sin elegir una posibilidad entre muchas otras, la selección que uno efectúa ya implica, por sí misma, una manera determinada de organizar lo real, segmentándolo. La selección que se hace constituye por lo tanto el equivalente de un primer análisis y de una interpretación implícita. Dicho de otro modo, ni los procedimientos concernientes, en semiótica, a la delimitación de un corpus textual o la clausura de un espacio de interacción tomado por objeto, ni aquellos relativos a la constitución de los datos para una investigación antropológica, son operaciones neutras respecto del trabajo 
de análisis o de interpretación "propiamente dicho", que, según el buen sentido, debería seguir cronológicamente. ¿De qué tipo son, entonces, los criterios posibles para fijar el objeto?

Muy a menudo, ante esa cuestión -manera cómoda de eludirla, más bien que de resolverla-, la segmentación de lo real con la cual el investigador se contenta no es otra que aquella que le proporciona el grupo social que toma, espontáneamente o por elección deliberada, como su "informador". Por ejemplo, cuando un semiótico emprende la tarea de desarrollar una semiótica de la "literatura", y para eso decide analizar determinadas obras consideradas como literarias, ¿qué hace sino identificar el "objeto literario" a partir de los criterios de reconocimiento vigentes en los medios académicos o en los de la crítica? Es decir que para construir su corpus, se confía en las autoridades informadas, y no en criterios semióticos -y con razón, pues por hipótesis, en ese estadio, tales criterios no existen todavía. Tal vez no haya otro punto de partida posible, pero el trabajo semiótico no comenzará antes del momento en que el investigador trate de sustituir los criterios que le ofrece su informador social por una definición semiótica de la "literariedad". ¡Tarea de largo aliento, como es sabido! A menos que dicho semiótico se proponga, más modestamente, dar cuenta de la manera como la cultura considerada construye, ella misma, la noción de objeto "literario" -en cuyo caso su trabajo se acercaría mucho al de un antropólogo, el cual, como se sabe, partiendo también de las categorías con cuya ayuda el informador (en este caso, el "indígena") describe su propia cultura, trata de superarlas con vistas a dar cuenta de ellas en un plano teórico más general.

Dicho de otro modo, la postura epistemológica adoptada depende del tipo de relación que el investigador establece con su informador, de conformidad con el tipo de rol que le atribuye. Según la perspectiva semiótica, puede desempeñar el papel de "informador" cualquier instancia susceptible de ser constituida en fuente de saber por iniciativa de algún observador. Hasta las cosas inanimadas -un paisaje, la topografía de una ciudad-tienen, pues, semióticamente, vocación de informadores puesto que, por el simple hecho de aparecer, dicen algo de sí mismas desde el momento en que alguien posa su mirada sobre ellas. De la misma manera, como sabemos por experiencia, nuestro rostro cumple, independientemente de nuestras intenciones y muchas veces a pesar nuestro, el rol de un informador para otro en la medida en que, interpretándolo desde el exterior, cada cual puede (acertadamente o engañándose) leer en él la expresión de nuestros supuestos estados de ánimo. En cambio, en antropología, conforme al uso lexical corriente, el término "informador" se emplea para designar un tipo de actores más restringido, a saber, una clase de sujetos dotados a la vez de competencia 
cognitiva y de intención, y de los cuales, en determinadas condiciones, otros sujetos, a su vez cognitivos e intencionales -simples curiosos o encuestadores profesionales-, pueden esperar la comunicación de una parte del saber que se supone que poseen.

En la tensión entre esas dos acepciones de la noción de informador se centra el problema de la construcción del objeto de análisis de las dos disciplinas consideradas. Tenemos ahí, en efecto, el esbozo de dos regímenes epistémicos que, aunque muy diferentes y hasta opuestos entre sí, impregnan las prácticas de investigación de una y de otra disciplina. Ambas están oscilando entre dos problemáticas posibles para la construcción del saber: por un lado, una visión clásica, con carácter objetivante, y por otro, una concepción intersubjetiva. Durante mucho tiempo, en el marco de la antropología más clásica y de la semiótica estructural, se consideró que solo la mirada del investigador tomaba parte activa en la construcción del objeto de conocimiento, mientras que el "otro" -el informador- era reducido al estatuto de un no-sujeto: el "salvaje" (el "primitivo"), el autor de un texto literario, o, más generalmente, el actor social "no saben": no conocen ni pueden conocer la razón de lo que piensan, y no tienen cómo dar cuenta de lo que hacen. Solo el sabio, apoyado en su posición exterior, está en condiciones, por medio de análisis metódicamente conducidos, de alcanzar un nivel de significación profunda detrás de las manifestaciones producidas en forma de textos, de objetos materiales, de comportamientos o de prácticas, o simplemente de respuestas a las preguntas de algún investigador.

La problemática alternativa se funda, al contrario, en la idea de que la comprensión del otro y de las manifestaciones significantes que produce no puede resultar más que de un diálogo entre observador e informador -mejor, de una verdadera interacción entre analizante y analizado. Según esa perspectiva, en lugar de observar al otro a distancia como si fuese un objeto, se le otorga plenamente el estatuto de un sujeto. Y frente a él, el analizante tiene que comprometerse en una relación de tipo intersubjetivo. Esa opción, particularmente cara a los antropólogos "postestructuralistas" aunque no únicamente a ellos, comporta, para el analizante, un riesgo: puede llegar hasta olvidar que su objetivo reside en dar cuenta del sentido de las acciones o de los discursos que encuentra, y termine por no preocuparse más que de sus propias reacciones y de sus estados de ánimo frente al otro. ¡Sustituir por un proceder introspectivo de ese género los procedimientos analíticos de antaño sería reducir el trabajo del antropólogo o del semiótico a bien poca cosa! Se trata, en cambio, de considerar que, en el frente a frente entre analizante y analizado, cada uno pone a prueba al otro, no psicológicamente sino en el plano de sus principios respectivos 
de comprensión del mundo, de tal modo que, por un proceder dialéctico próximo a aquellos, familiares a los fenomenólogos, la interacción entre "sujeto" y "objeto" pase a ser el propio lugar de emergencia de un sentido nuevo - un sentido que, sin pertenecer específicamente ni a uno ni a otro, no puede resultar más que de las modalidades de su encuentro.

Lo que cambia cuando se pasa de un polo de la alternativa al otro es, entonces, la naturaleza del conocimiento que se intenta lograr: por un lado, un saber unilateral sobre el otro y, por así decirlo, a pesar suyo, y por el otro, un saber interaccionalmente elaborado con él como sujeto. Por supuesto, siempre es posible no tener en cuenta dicha tensión y optar por un polo o por el otro, es decir, por una forma u otra de reduccionismo: o regresión a un positivismo cuyos límites son suficientemente conocidos $\mathrm{o}$, al contrario, fuga hacia un puro subjetivismo (el "deconstruccionismo"). Sin embargo, las cosas serían demasiado simples si la opción se planteara en términos tan categóricos. En realidad, basta con observar las prácticas de los investigadores en ambos campos disciplinares para constatar que las dos concepciones, por más que se opongan en términos epistemológicos, cohabitan en el plano de las diligencias heurísticas, dando lugar a toda suerte de procedimientos de búsqueda y de interpretación de carácter híbrido. ¡No solo nosotros nos permitimos jugar con las distintas acepciones de la palabra "informador"! Hoy en día, muchos antropólogos, y también algunos semióticos (o sociosemióticos), aunque traten de mantenerse a una distancia objetivante, están, al mismo tiempo, conscientes de su propia implicación en la relación con su "objeto", es decir, en la mayor parte de los casos, directa o indirectamente, con otro sujeto. También ellos juegan "en los dos tableros". No lo hacen por amor al compromiso ni por debilidad metodológica, sino porque la tensión entre los dos polos de la alternativa forma parte de los datos constitutivos de nuestras investigaciones en las ciencias humanas (Landowski, 1999).

Lejos de reducirse a un mero debate académico, el problema afecta por lo tanto a las condiciones y a la significación del trabajo mismo de investigación. Eso nos incita a confrontar dos estudios emanados, respectivamente, de una y otra disciplina, y ambos intentan dar testimonio de una visión dialéctica -y no categórica. Se trata, por un lado, del libro de Paul Rabinow Un ethnologue au Maroc (1988), "reflexión sobre un trabajo de campo" que ilustra la complejidad de los regímenes de sentido y de interacción que entran en juego en la construcción de cierta forma de saber antropológico a través del encuentro con el otro; y, por otro lado, de un modelo que hemos elaborado, en términos semióticos, para pensar la articulación entre varios regímenes de construcción del sentido en la interacción (Landowski, 2005). 


\section{Regímenes de interacción}

El modelo interaccional que proponemos ha sido construido a partir del esquema narrativo propuesto por Greimas, con vistas a ampliarlo ${ }^{1}$. Para introducirlo, comencemos por algunas generalidades. Cualquiera que sea el proyecto que pretendamos realizar, el problema que queramos resolver o el asunto que deseemos llevar a cabo, es un hecho empíricamente constatable que cada cual, en la vida cotidiana y a fortiori en los momentos más graves, se siente inclinado (en función de su cultura o de alguna idiosincrasia personal) a privilegiar cierto estilo de acción, un modus operandi determinado, un tipo de "estrategia" de preferencia a tal otro. Algunos, por ejemplo, no sintiéndose a gusto más que en un ambiente bien ordenado, soñarían con poder programar tanto el comportamiento de los que los rodean como el orden de las cosas a fin de asegurar hasta el mínimo detalle el control del desarrollo de la más pequeña operación en la que se hallan implicados. Otros, al no ver por todas partes más que maquinaciones y complots, pensarían que no podrían llegar a obtener sus fines sino manipulando, con los rodeos que fuesen necesarios, a aquellos con los que tienen que tratar. Otros, en cam- bio, preferirán fiarse de su intuición, de su olfato, de su capacidad de sentir en el momento mismo, en acto, los pormenores de una situación o las disposiciones íntimas de aquellos con los que entran en relación, dispuestos a ajustarse a ellos y a sacar el mejor partido posible de la interacción, "cogiendo la ocasión por los cabellos". Otros, finalmente, descartando toda idea de plan previo, de cálculo o de sintonía con el otro, creerán que es más seguro atenerse a su buena estre1la, a la suerte, y se contentarán con cruzar los dedos, esperando algún feliz accidente que la providencia habrá destinado para ellos.

Retomando la expresión de Merleau-Ponty, estas son otras tantas maneras de estar en el mundo, que corresponden, cada una, a un modo específico de construir el "sentido de la vida" y se traducen en estilos de conducta diferenciados en relación con los objetos, con los otros y consigo mismos. Si esas variantes comportamentales resultasen simplemente de determinaciones psicológicas, lo único que tendríamos que hacer sería constatarlas. Pero los regímenes de sentido y de interacción a los que corresponden se articulan unos con otros, como vamos a verlo, en función de principios estructurales que nada deben a la psicología. Es

1 Para una presentación de los elementos de base de la gramática narrativa, véase Greimas/ Courtés (1979), en particular, las entradas: "Narratividad", “Sujeto", “Sintaxis narrativa". 
eso lo que los vuelve semióticamente analizables. Sin embargo, entre esos modos de actuar que nos resultan intuitivamente familiares, la semiótica narrativa clásica no había reconocido ni tematizado más que dos: la "programación", por lo que refiere a las acciones sobre las cosas, y sobre todo la "manipulación", entre sujetos. Examinando cómo funcionan esos regímenes, es fácil observar que el primero se funda en un principio general de regularidad-principio que se manifiesta por la inmutabilidad de los roles asignados a los protagonistas de la acción y que garantiza (en principio) la eficacia de nuestras intervenciones sobre el mundo que nos rodea- y que el segundo tiene por base un principio de intencionalidad, en función del cual los partícipes de la interacción se definen, y se reconocen recíprocamente, en cuanto sujetos dotados de "competencias modales" variables (del tipo del querer, creer, saber, poder). De ese modo, la gramática narrativa ha puesto en lugar de honor la figura del manipulador, y accesoriamente, la del programador.

En cambio, ni el sujeto que confía en su capacidad de sentir in vivo las potencialidades de una situación, de volver en ventaja la propensión de las cosas y de las gentes, de captar y de explotar de improviso el kairós -llamémosle el oportunista- ni el fatalista decidido a someterse cueste lo que cueste a lo que le acontece, encontraban lugar en aquel marco. La observación de la interacción, y en primer lugar la experiencia misma que todos tenemos de ella, nos obligaban no obstante a tomarlos semióticamente en cuenta. Para poder analizar, por poco exhaustivamente que sea, el abanico de los regímenes de construcción del sentido que las prácticas relacionales efectivas suponen, era, pues, indispensable ampliar el alcance de la gramática narrativa. De ahí nuestra iniciativa de introducir al lado de los dos regímenes "estándar" ya mencionados -y que, si pierden su monopolio, no por eso pierden nada de su pertinencia-, dos regímenes de interacción complementarios, fundados, respectivamente, en un principio de sensibilidad y en un principio de suerte: el régimen del "ajuste" al otro, cualquiera que este sea, y el régimen del "asentimiento" a los decretos de la suerte: 


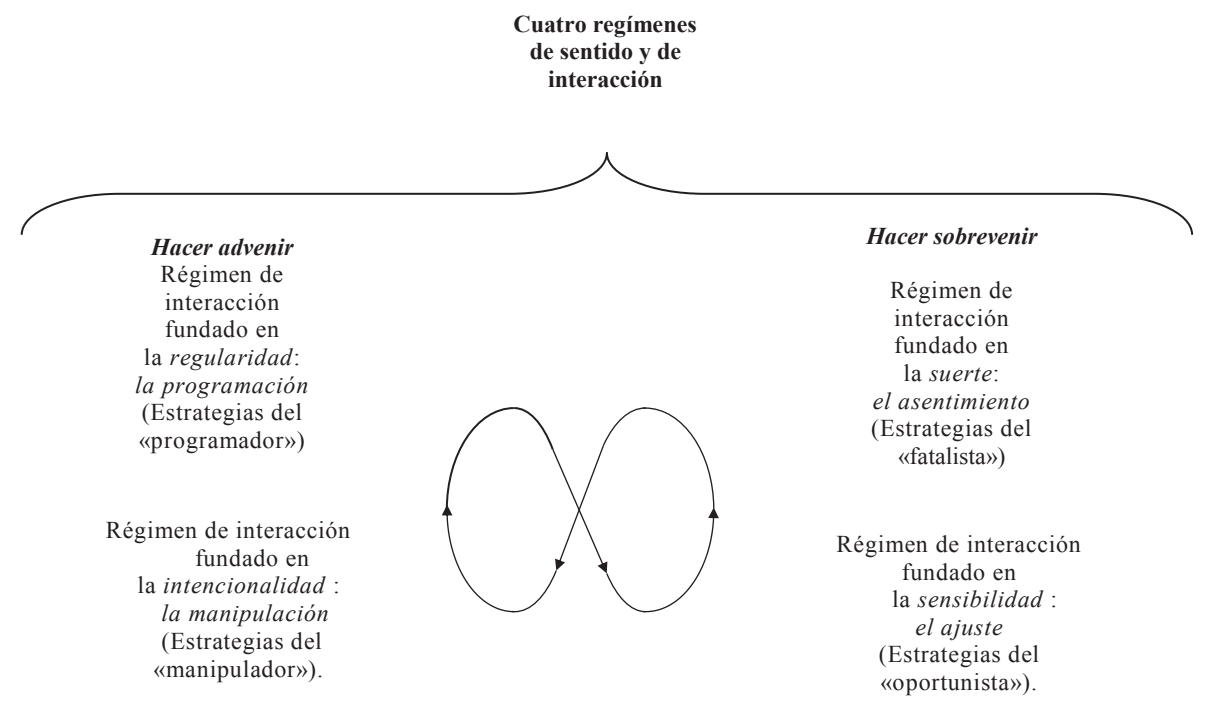

Hacer sentir

Hacer querer

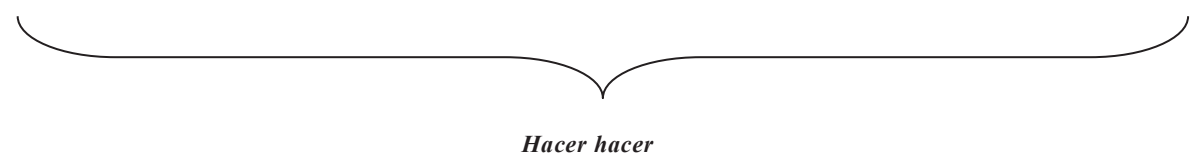

Formando sistema y con vocación de articularse y de combinarse entre sí, las cuatro fórmulas a las que así llegamos permiten, a nuestro modo de ver, dar cuenta de la variedad y del carácter generalmente heteróclito, híbrido, polivalente de las prácticas interaccionales observables en los campos más diversos, incluido el de la construcción del objeto de conocimiento en nuestras disciplinas con pretensiones científicas.

En el interior de ese dispositivo, ¿cuál podría ser el lugar del etnógrafo? ¿El de un hábil manipulador? ¿El de un sutil oportunista? ¿Qué más? O bien, dado que este modelo tipológico cumple también la función de diagrama topológico (lo cual se trata de indicar con el trazado orientado de la elipse), ¿cuáles podrían ser los recorridos que el encuestador efectuaría si por fuerza de las circunstancias o en función de los contextos se ve llevado a cambiar de posición y a pasar de un régimen a otro? Más ampliamente, ¿en qué medida las estrategias relacionales definidas por la sintaxis del modelo y las posturas que cada una implica frente al Otro permiten dar cuenta de niveles específicos, de concepciones particulares o de 
momentos determinados que afectan a la praxis etnoantropológica en cuanto búsqueda de saber?

Para responder, al menos en parte, a este género de cuestiones, nos apoyaremos ahora en la lectura del libro ya citado de Paul Rabinow, cuyo interés radica para nosotros en el hecho de que se sitúa a medio camino entre el relato de una "experiencia vivida" y la reflexión de orden epistemológico -O mejor, porque logra articular con éxito y con finura las dos hojas de ese díptico.

\section{Un epistemólogo en acto}

Al hilo de la narración, el autor -o más exactamente el narrador, tal como se pone él mismo en escena- encuentra una serie de informadores potenciales. Con algunos de ellos, el encuentro fracasa de inmediato. No debemos por eso ignorarlos. La confrontación del texto de Paul Rabinow con nuestro modelo sería sesgada si no tomásemos en cuenta más que algunos elementos del primero, pasando los otros en silencio. Además, el sistema de compatibilidades e incompatibilidades entre los regímenes interdefinidos en el marco de este modelo nos permite, en particular, esbozar una teoría del error estratégico, del quid-pro-quo, del equívoco, en breve, de la interacción fallida (Landowski, 2005, pp. 54-55). Comencemos entonces por los fracasos y los encuentros abortados.

Richard, Ibrahim, Mekki: otras tantas decepciones para nuestro héroe, " $\mathrm{M}$.
Paul", el narrador. Su principio común es simple e inmediatamente deducible de la combinatoria que el modelo nos invita a construir. Para que haya interacción es necesario, como mínimo, que existan dos actores; si postulamos que cada uno de ellos privilegia necesariamente un régimen de sentido y un modo de interacción determinado (sea de manera general, sea en determinada situación concreta), podemos definir deductivamente una serie de esquemas de encuentro virtuales (dieciséis para ser precisos) haciendo el inventario de las combinaciones posibles, dos a dos, entre el estilo estratégico que adoptará uno de estos actores y aquel -idéntico o diferente- que guiará la respuesta del otro. Es previsible que de cada uno de esos esquemas resultarán efectos de sentido distintos $\mathrm{y}$, al mismo tiempo, efectos pragmáticos diversificados, desde el éxito casi garantizado hasta el fracaso asegurado.

Sin entrar en el detalle de tal cálculo, admitamos, por ejemplo, que para que las conductas de un adepto al régimen de la programación tengan las mejores oportunidades de éxito en el plano pragmático sea necesario (y probablemente suficiente) que vayan al encuentro de un "partenaire" a su vez ya programado (como una computadora) o, por lo menos, "programable" (como el perro de Pavlov); que, igualmente, un manipulador, para estar seguro de tener éxito, necesita interlocutores algo "manipulables"; y así sucesivamente. Tales concordancias no tienen nada de excepcional. Sin 
embargo, no siempre podemos elegir con quién vamos a interactuar. ¿Qué pasará entonces cuando un programador tenga que enfrentar a un fatalista, a un oportunista o a un manipulador? $\mathrm{O}$ recíprocamente. Debemos esperar sin duda que, en tales casos, se presenten desengaños de tipos cualitativamente diferenciados, en función de la diversidad de mal-emparejamientos posibles entre los regímenes a los que se sometan, respectivamente, cada una de las dos partes enfrentadas.

Los infortunios de M. Paul proceden sistemáticamente de uno de esos diversos casos previsibles. Como buen etnógrafo, no está dispuesto a contentarse con informaciones fijadas en discursos convencionales que le parezcan preprogramados por el medio ambiente. Lamentablemente, Richard, la primera persona con la que entra en contacto, solo sabe repetir indefinidamente los mismos clichés sobre la vida local. Ibrahim, a continuación, con el que cuenta para iniciarse en el árabe, se muestra orgulloso de su lengua, pero su enseñanza se reduce al recitado de listas del vocabulario halladas en un viejo manual. En cuanto a Mekki, sin el menor intento por distanciarse de su propio universo social y cultural, permanece prisionero de esquemas dogmáticos por todos aceptados. Al cabo de muy poco tiempo, el etnólogo se da cuenta de que sería en vano esperar que tales interlocutores pudieran interesarse en el género de intercambios intelectuales que él busca, ya sea tratando de manipularlos o de ajustarse a ellos: por lo menos en lo que concierne a sus relaciones con un visitante extranjero de su género, no son más que no-sujetos, es decir, actores de comportamiento rígidamente programado.

Ahora bien, si entre dos interlocutores, uno u otro-aquí es el informador, en otro momento podría ser el encuestador- se encierra en el marco de una programación discursiva determinada, eso evidentemente afecta el estatuto de la información transmitida y, desde un punto de vista antropológico, a su valor. Un "buen" encuestador debería por lo tanto ser capaz, al menos, de dos cosas: de identificar las respuestas prefabricadas que se le ofrecen, y de encontrar (cuando sea posible) los medios de sustituir las relaciones intersubjetivas convencionales que su postura profesional tiende a suscitar por un régimen de interacción más abierto, que le permita obtener del encuestado un discurso más libre $y$, como consecuencia, con un poco de suerte, más ilustrativo. Recíprocamente, un "buen" informador sería aquel que, siendo capaz, primero, de reconocer el carácter convencional de las preguntas que un etnógrafo demasiadamente programado (demasiado inclinado a seguir al pie de la letra los manuales de método y las guías de comportamiento en el trabajo de campo) se sentiría obligado a proponer a su interlocutor -el encuestador- plantearse a sí mismo preguntas menos manoseadas y dirigirle -a él, el encuestado-, preguntas menos aburridas y tal vez, por eso mismo, más juiciosas. 
No nos detendríamos en la idea, un tanto impertinente aunque rigurosamente lógica, de una tal inversión de roles, si el relato de Paul Rabinow no hubiera subrayado hasta qué punto el encuestador necesita una participación activa del encuestado para que el intercambio sea fructuoso. Veamos a ese respecto qué sucede en los encuentros del narrador con Ali, con Rashid, y luego con Malik, y finalmente con Driss ben Mohammed.

"Ali era un informador excelente". El texto lo describe como un hombre de carácter, de espíritu y de comportamiento muy libres (a tal punto que se halla socialmente marginalizado), y siempre lleno de iniciativas. ¡Es casi un pequeño bandido! "M. Paul" le debe, sin embargo, mucho, incluso en el plano a primera vista extraprofesional. Guiado por él, pasará "el día más bello" que podría pasar en Marruecos (Rabinow, 1988, pp. 64-70). Ese día, a Ali se le ocurrió la idea de invitarlo a un paseo de montaña con dos de sus amigas, durante el cual se va dejando llevar a una "experiencia sorprendente", con la que irá perdiendo poco a poco, con arrobamiento, todas sus referencias habituales: "No sabía adónde íbamos [...] me daba cuenta de que las secuencias no obedecían a ningún plan, no tenían ninguna coherencia, que las orientaciones y las relaciones causales eran engañosas [...]; sentía un júbilo creciente, como si abandonásemos toda inhibición personal, toda convención social". En una palabra, "era la aventura". Ninguna norma ordinaria de conducta, ninguna programación del tiempo, de la acción, del discurso tenía lugar: nuestro héroe se encuentra transportado a un mundo en los antípodas de la regularidad tranquilizante de la vida cotidiana, un mundo donde todo-es-posible, donde el accidente feliz, el que se consiente de antemano, puede ocurrir: "nos dejábamos llevar simplemente por la ola de los acontecimientos". No se podría ilustrar de mejor manera eso que llamamos régimen del asentimiento a la suerte.

El "sentimiento de euforia y de amical complicidad" experimentado con ocasión de esa idílica jornada por los dos compinches (que no dejan de ser por eso, uno frente a otro, "el etnólogo" y su "informador") contribuirá a reforzar entre ellos un lazo ya establecido en el marco de otro régimen más prosaico: el de la manipulación recíproca. El relato no ofrece precisiones sobre la manera como el etnólogo obtiene día a día la cooperación de Ali. Se limita a evocar las motivaciones generales, "sobre todo pragmáticas" según él, que supone en el otro, y que, por lo demás, serán las mismas que se darán después en los casos de Malik y de Rashid: a cambio de su colaboración con el antropólogo, cuentan con un pequeño ingreso, eventualmente con alguna ayuda o servicio (en un momento dado, M. Paul tendrá que servir de chofer a casi toda la aldea) y con cierto "aire" de prestigio ante sus familiares y conocidos (sobre todo en el caso de Rashid, que "se pavonea 
con la notoriedad adquirida por su trabajo con el etnólogo").

A ese estilo de relaciones interpersonales corresponde de nuevo una delimitación bastante precisa de la naturaleza y del valor de la información recogida por el etnólogo. Con Rashid, y más aún con Malik -con este último, ese régimen de intercambios adquirirá la forma de un verdadero contrato, renovable mes a mes-, la colaboración difícilmente superará los límites de un trabajo "bastante mecánico" referido a tareas "bien delimitadas", tales como el trazado de las genealogías, la descripción del régimen de propiedades, de la red de irrigaciones o del sistema de parentesco. Dicho de otro modo, ambos interlocutores se mantienen en el marco de una epistemología objetivante de estilo clásico, y eso en la misma medida en que la interacción se inscribe estrictamente en el marco de relaciones contractuales. Mejor aún, cuanto más formalizadas son esas relaciones, más estrecho resulta el marco epistemológico del trabajo de encuesta llevado en pareja.

Por el contrario, con Ali se trata de un lazo de afinidad recíproca, de orden puramente "amical", la cual, a pesar de algunas desavenencias pasajeras, va a estrecharse y a expandirse a base de "relaciones de reciprocidad libres y sin coerciones, un tanto indefinidas". En ese marco, Ali aportará al etnólogo una ayuda decisiva para profundizar la problemática que le preocupa. En términos de nuestro modelo, esa nueva forma de relación nos hace pasar del régimen de la manipulación al régimen del ajuste, régimen más arriesgado en el que la interacción se juega con frecuencia en los límites del accidente. Ali revela ser excelente en ese contexto relacional. Y el etnógrafo se muestra a su altura, especialmente en ocasión de un incidente que aquí es preciso resumir (Rabinow, 1988, pp. 48-55).

Ali, una vez más, había invitado a monsieur Paul a acompañarlo, en este caso a un matrimonio. Le había prometido que no se detendrían mucho tiempo. Pero esa promesa no será cumplida: una vez en el lugar, mientras que la fiesta se prolonga hasta altas horas de la noche, el etnólogo espera, se aburre, se irrita y su irritación crece a medida que las horas pasan. Después de lo cual, ya en el camino de retorno, al volante, enfurruñado, le pregunta Ali: “¿Estás contento?”. Y luego insiste: "Pero ¿por qué estás de mal humor?". Y finalmente, después de otra repetición, abre la puerta del carro y amenaza saltar en marcha: "Si estás descontento, entonces regreso a pie". El etnólogo detiene el automóvil, lo deja bajar y arranca sin él -la muerte en el alma: ¿la desavenencia será definitiva?

En términos narrativos, la provocación, de la que tenemos aquí un buen ejemplo, constituye una de las figuras de la manipulación. En la ocurrencia, sin embargo, Ali no trata de hacer hacer a M. Paul nada en particular, y ciertamente no pretende obtener que lo haga bajar del auto. Desafiándolo a que lo abandone en pleno descampado, no busca ningún objetivo de orden 
pragmático. Su única meta es ponerlo a prueba, medir su grado de resistencia, evaluarlo en cuanto partícipe de una interacción que podrá terminar allí mismo si el otro no se muestra a la altura, o bien, al contrario, constituir un nuevo punto de partida si revela ser capaz de responder adecuadamente a su gesto. Un poco por azar, resulta que la firmeza de la que el antropólogo da testimonio con su reacción constituía la buena respuesta -la respuesta justa- desde el punto de vista de su copartícipe. Por su intransigencia, monsieur Paul permite en efecto que Ali sienta que tiene frente a sí un hombre, si se puede decir, de su propio temple. La manipulación no era más que una suerte de trampa, un procedimiento táctico subordinado a un fin estratégico que lo sobrepasaba. Solo habrá servido para atestiguar la posibilidad de un ajuste entre dos hexis, entre dos maneras de ser-en-el-mundo².

“En otra situación, tal vez mi gesto sería considerado irreparable. Pero en Marruecos, jugar con el fuego es algo usual, cotidiano, y usarlo con fineza, una necesidad vital". A decir verdad, no solo en Marruecos es preciso "jugar con fuego" para que dos sensibilidades, dos temperamentos o incluso dos espíritus (por poco vivaces que sean) lleguen a ajustarse mutuamente. La aceptación del riesgo de catástrofe, el asentimiento anticipado al accidente eventual, representa al contrario de una manera general un dato constitutivo de ese régimen de "ajuste" en el que, por construcción, las potencialidades de la interacción no se revelan plenamente más que al borde de la ruptura posible entre los protagonistas. De hecho, después de ese enfrentamiento que hubiera podido terminar en una ruptura definitiva, los lazos entre los dos hombres, en lugar de distenderse, se estrechan más: “a partir de entonces, fuimos los mejores amigos del mundo". Y eso no deja de tener consecuencias en el plano de la búsqueda etnográfica: "Solo después de aquel incidente, Ali comenzó a revelarme dos aspectos de su vida que hasta ese momento había disimulado".

Sin embargo, la tarea de un etnógrafo no consiste simplemente en establecer buenas relaciones con sus informantes, lo que equivaldría a retribuir con unas sonrisas las "revelaciones" puntuales que hubieran aceptado hacerle. Lo que más importa es el hecho de que, aquí, una vez más, el paso de un régimen de sentido y de interacción a otro conlleva un salto cualitativo que concierne también a las modalidades de interacción entre encuestador y encuestado en el plano cognitivo mismo. A partir del momento en que dos copartícipes han probado,

2 El narrador pone de relieve, al pasar, otra táctica que acostumbra a utilizar Ali para "sondear al otro": su humor, "más explosivo y personalizado" que las "bromas mesuradas" que utilizan los otros informantes. 
como Ali y su chofer de ocasión, que pueden "entenderse" por ajustes sucesivos en un plano en cierto modo existencial, hay grandes posibilidades para que entre ellos se abra la oportunidad de interactuar positivamente en términos comparables en el plano intelectual. Eso es lo que el narrador confirma: "con Ali llegamos a encontrar un terreno de entendimiento y de experiencias comunes arreglado gracias a nuestros mutuos esfuerzos, un dominio común de sentido". La forma de su confrontación, en la que cada uno, con pequeñas provocaciones, sondea al otro y lo fuerza a sobrepasar su propio límite, es idéntica en los dos planos. A lo largo de su trabajo de reflexión sobre aquello en que consiste la alteridad de cada uno frente al otro, al mismo tiempo que frente a la realidad social y política que han tomado en común por objeto, cada uno de ellos, a su turno, se siente "perturbado en su proceder habitual", así como cada uno había quedado turbado por el gesto del otro en el incidente del matrimonio. Es decir que en el plano intelectual como en el plano afectivo y psicológico, el ajuste es un proceso "dialéctico" según la aceptación que adquiere este término en la pluma del Paul Rabinow: "ni el sujeto ni el objeto permanecen ahí estáticos".

En el marco contractual característico del régimen de la manipulación, se le había ofrecido ya al etnógrafo cierta cantidad de información, proporcional a lo que podía ofrecer a cambio. Todavía, en tal contexto regulado bajo el modo del "donante por donante", el intercambio tenía que limitarse a transferencias de objetos, unos cognitivos, otros no (dinero, servicios, regalos), pero todos de carácter discreto $y$, de preferencia, con valor cuantificable. En cambio, bajo el régimen del ajuste, lo que está en juego no es la transmisión de informaciones a cambio de una justa contrapartida, sino la producción misma de una forma de conocimiento totalmente diferente, ya que, lejos de preexistir -como una mercancía en depósito- al establecimiento de un contrato entre los participantes de la comunicación, se trata ahora de un saber que debe ser elaborado por ellos mismos, conjuntamente, de suerte que si logran efectivamente construirlo, existirá solo como el fruto de su cooperación. Por consiguiente, aquí no se puede utilizar la distinción de buen sentido entre una fase inicial de "recolección" de informaciones y una fase ulterior de trabajo de "interpretación". Más aun, ya no hay propiamente hablando ni siquiera "datos" que recoger, sino, según los términos de Paul Rabinow, una pura "relación de interacción entre encuestado y encuestador". La forma del saber antropológico que se construye en pareja en el espacio de esa relación está, por construcción, más cerca de la comprensión fenomenológica que de una problemática de la información y de su tratamiento.

Se comprende así que sea a Ali, ese maestro del ajuste, a quien el narrador declara en conclusión deber su "aprehensión de la cultura marroquí en su 
inmediatez, en cuanto experiencia vivida". No obstante, el mismo narrador nos dice que, aun más que con sus demás informadores, fue con Driss ben Mohammed con quien pudo sentir la posibilidad de "ir más lejos". Con él, la experiencia de campo iba a alcanzar "profundidades afectivas e intelectuales nuevas". La lectura del breve capítulo final, consagrado precisamente a ese último encuentro, deja incierto por qué razón este encuentro constituye a los ojos del narrador la experiencia más rica de todas. De hecho, encontramos allí el conjunto de los componentes descubiertos a lo largo de los desarrollos precedentes: la suerte y su contrario, la programación, aunque virtualizada: "Al azar, sin proyectos o programas concertados [...] tuvimos una serie de conversaciones sin orden ni concierto"; la manipulación, evocada igualmente en negativo: "Ben Mohammed no tenía miedo de mí [...], tampoco trataba de sacar provecho de mí (rehusaba incluso los regalos)"; y, por encima de todo, el ajuste. Finalmente, la profundidad excepcional de esa amistad ¿no tendrá que ver con la forma de ajuste particular, "de espíritu a espíritu", al que llegan los dos hombres, una forma - ¿sublime?- que se despliega en una relación intelectual aparentemente liberada del contexto social?

Todos los otros informadores estaban fuertemente influenciados, hasta en su manera de pensar, por la presión de su medio. Mekki, ejemplo típico del locutor programado, que había sido "literalmente impuesto" al etnólogo por la aldea, habla una lengua totalmente estereotipada. "Para eso, ningún remedio". Malik, aunque de espíritu mucho más sutil, no habla tampoco libremente: conservador, afectivamente muy solidario con su grupo, se deja manipular por la comunidad: "era el perfecto representante de la ortodoxia". En el lado opuesto, Rashid y Ali, ambos "en posición inestable" con relación a la vida aldeana, permanecen a pesar de todo "imbricados en la red de su propio universo local"; sus discursos de "rebeldes" y su lado "aventurero", deliberadamente cultivados para oponerse a la comunidad, no son más que su reflejo invertido. Los encuentros con Driss ben Mohammed escapan a todo eso. Se desarrollan lejos de las rutinas cotidianas así como a buena distancia de las intrigas y de las manipulaciones del pueblo. E, impregnados de una suerte de serenidad bucólica, no dan tampoco lugar a la espera de acontecimientos aleatorios o providenciales. "Estábamos sentados en las faldas de una ladera bajo unas higueras como un par de amigos pasando juntos una calurosa tarde de verano bajo un cielo sin nubes": espacio ideal para una investigación concebida como forma de vida a la vez interior y compartida, casi a la manera socrática.

Con esta escena termina el libro, o mejor, su parte narrativa. Porque el relato de esa serie de encuentros está enmarcado por dos fragmentos de otra 
naturaleza: una conclusión del autor que saca la "moral" -antropológicadel relato, y, en la edición francesa, un prefacio de Pierre Bourdieu, que opina, magistralmente, sobre el conjunto de la obra. Entre los dos, el discurso de "M. Paul", héroe a lo Ulises ("Salí de Chicago... estoy de regreso" -pp. 15 y 133), y, a la vez, narrador de su propia Odisea. ¿Quién es, finalmente, ese "yo" a quien se le delega la palabra narrativa? ¿Un puro simulacro enunciativo, creado por la magia de una escritura hábilmente elaborada? ¡Por último, es posible que no haya habido ningún "etnólogo en Marruecos" de nombre "M. Paul"! Tal vez toda esa aventura no es más que ficción... ¿Y si "Paul Rabinow", o el que ha puesto ese nombre en la cubierta del libro, no fuese más que un buen hacedor de novelas? En ese caso, la novela es buena, y eso es lo que importa -desde dos puntos de vista. Desde el estético, pues se lee con sumo agrado. $Y$ desde el científico, porque el texto pone en escena el procedimiento mismo de un trabajo de investigación y las condiciones de la producción de un nuevo saber. Desde este punto de vista, "M. Paul", simple ser de papel o (más probablemente) verdadero etnólogo en Marruecos, es un auténtico epistemólogo, y lo que es más, en acto. Su aventura cognitiva reviste un alcance general, $\mathrm{y}$ en eso reside su valor.

La búsqueda de inteligibilidad que nos es contada muestra en efecto cómo, a cada uno de los regímenes de interacción por los que pasa, corresponde un régimen de saber diferente. De uno de esos al otro, el carácter interactivo del proceso de conocimiento está desigualmente marcado.Cuandoeletnógrafotieneque hacer con un locutor programado (que no sabe más que recitar su lección), el encuestador y solo él tiene que actuar, y aun así bien poco: su rol se limita entonces a engarzar (según una suerte de esquema de estímulo-respuesta) la recitación por el encuestado de un discurso ya preparado de antemano. $Y$ si, por el contrario, fuese el etnógrafo mismo quien estuviera demasiado "programado", si no hubiera aprendido a ver en el otro más que la imagen que de él da su propia cultura, habría aún menos oportunidad de interactuar con sus informadores, pues, en ese caso, solo le bastaría con observarlos desde el exterior para encontrar en ellos todo lo que ya sabía antes de encontrarlos (cf. Landowski, 1977, pp. 99-104). Por otra parte, también el régimen de la suerte da lugar a una relación de coeficiente interactivo muy débil, ya que en tal contexto lo mejor que puede hacer el encuestador es esperar lo más pacientemente la revelación providencial que el otro le proporcionará por accidente, sin querer y probablemente sin saberlo, e incluso sin que nada se la haya pedido.

En cambio, en las otras dos configuraciones se da interacción en el sentido pleno del término. Entre manipulador y manipulado, la transmisión del saber se inscribe en un marco a la vez contractual, en el 
que cada uno tiene que defender sus propios intereses, tanto pragmáticos como cognitivos, y dialógico, donde las respuestas del encuestado se dan en función de la pertinencia de las preguntas del encuestador. El saber es ahí la "puesta" de toda una serie de estrategias: se persuade, se promete, se provoca. Pero esas interacciones no escapan a un marco funcional -se manipula para saber-, y el saber que los participantes tienen que "ganar" sigue siendo algo exterior al interactuar como tal. Por el contrario, los dos aspectos, conocimiento e interacción, se reúnen y hasta terminan por confundirse en la dinámica de esa suerte de danza de la interlocución que asume el proceso del ajuste mutuo: bajo este último régimen, es el proceso mismo de reconocimiento recíproco en el movimiento del pensamiento el que tiene valor de descubrimiento.

Nuestro propósito no era, por cierto, al comienzo, encerrar al etnólogo (ni menos al semiótico) en una o en otra de las casillas de un modelo predefinido. Mucho menos es esa nuestra intención a la llegada. Al contrario, la manera como el texto analizado conduce a precisar las condiciones de funcionamiento, las implicaciones y los límites respectivos de cada uno de los regímenes inventariados, y también las interferencias o los encabalgamientos que complejizan sus relaciones, nos invitan, sobre todo, a enriquecer el modelo.

\section{Referencias}

Greimas, A. J. y Courtés, J. (1979). Sémiotique. Dictionnaire raisonné de la théorie du langage. París: Hachette. [En español: (1982). Semiótica. Diccionario razonado de la teoría del lenguaje. Madrid: Gredos.

Landowski, E. (1997). Présences de l'autre. París: PUF. [En español: (2007) Presencias del otro. Lima: Fondo Editorial Universidad de Lima.

Landowski, E. (1999). "La mirada implicada". Anthropos (Barcelona), 186, pp. 37-56. [En francés: (2004) “Le regard impliqué", Passions sans nom. Essais de socio-sémiotique III, Paris: P.U.F. [En español: (2015). Pasiones sin nombre. Ensayos de sociosemiótica. Lima: Fondo Editorial Universidad de Lima.

Landowski, E. (2005). Les interactions risquées. Nouveaux Actes Sémiotiques, 101/103. Limoges: PULIM. [En español: (2009). Interacciones arriesgadas. Lima: Fondo Editorial Universidad de Lima.

Rabinow, P. (1988). Un ethnologue au Maroc [Un etnólogo en Marruecos]. (Prefacio de Pierre Bourdieu). París: Hachette. [Edición original: (1977). Reflections on Fieldwork in Morocco. With a foreword by Robert N. Bellah. Berkeley: University of California Press. 
